\title{
Xiangqi vs Chess-The Cultural Differences Reflected in Chinese and Western Games
}

Li Ma

School of English Studies, Xi'an International Studies University, Xi'an, China

Email:mali@xisu.edu.cn

How to cite this paper: Ma, L. (2020). Xiangqi vs Chess-The Cultural Differences Reflected in Chinese and Western Games. Open Journal of Social Sciences, 8, 52-61. https://doi.org/10.4236/jss.2020.83006

Received: February 16, 2020

Accepted: March 6, 2020

Published: March 9, 2020

Copyright $\odot 2020$ by author(s) and Scientific Research Publishing Inc. This work is licensed under the Creative Commons Attribution International License (CC BY 4.0).

http://creativecommons.org/licenses/by/4.0/

(c) (i) Open Acces

\begin{abstract}
Xiangqi (Chinese chess) and Chess (international chess) have much in common. However, because of the distinctions between China and the West in history, geography and cultural background, they also have many obvious differences in game rules. The purpose of this study was to explore these differences. In the beginning, the paper briefly introduces the two games. Then, by comparing Xiangqi and Chess, it looks into the differences in social structures between China and the West, the different thinking patterns of Chinese and westerners, and the geographic differences between China and the West. Through discussion on each aspect, the study finds that these differences reflect the characteristics of Chinese culture and western culture respectively.
\end{abstract}

\section{Keywords}

Xiangqi, Chess, Game, Difference, Culture

\section{Introduction}

Xiangqi, also known as Chinese chess, is a traditional Chinese board game. With its rich complexity and attractive magic, since it was originated 1500 years ago in North Zhou Dynasty of China, Xiangqi has been widely favored by Chinese people $(\mathrm{Xu}, 2004)$. On the other hand, Chess, also called international chess, commonly believed to have originated from northwest India during the Gupta Empire, is now very popular in western countries. In both China and the West, Xiangqi or Chess players can be found everywhere: in schools, chess clubs, families, parks, or even on the street (Lin, 1999). Some literary men even devote great energies to explore the profound symbolic meanings of the games.

Ah Cheng, a Chinese novelist, is well-known for his masterpiece The Chess King. In this novel, he discovered the characteristics of traditional Chinese philosophy of Taoism (Ah, 2019)_ “action through inaction” (Li, 2008) from the 
game of Xiangqi. And in the West, Chess Story is a famous novel about Chess written by the Austrian writer Stefan Zweig. According to his novel, Chess is a dose of medicine that helps the hero to escape from the lasting and cruel spiritual suffering imposed by the Nazis (Zweig, 2005).

The above two writers in their works talked about how the games helped people who suffered hunger or loneliness endure the suffering and overcome the difficulties they met. However, these works only tell us how the games influence the spiritual world of humans, but neglect the cultural meanings of the games. As different games are invented against different cultural backgrounds, this paper intends to discuss the cultural distinctions reflected in the two games.

There are four body parts in this paper. Part 2 is a brief introduction to the two different games-Xiangqi and Chess; the reader will have a glimpse of the two interesting games. In Part 3, the author will analyze the cultural differences shown by the chessmen in the two games. Part 4 will show how the two games reflect the different thinking patterns of Chinese and westerners. Part 5 will mainly talk about how the games reflect the different geographic differences between China and the West.

\section{A Brief Introduction to Xiangqi and Chess}

Xiangqi and Chess originated from different places and have obvious distinctions in their shapes and moves. However, their rudiments are simple and very easy to master. When a beginner learns the basic way of the moves of either of the two games, he or she can easily play either Xiangqi or Chess since they have a lot in common. Both of them are generally played on a piece of grid board, which is usually made of wood or plastic. At the start of either game, each player controls sixteen pieces. The object of the game is to checkmate the opponent's king or commander, whereby the king or the commander is under immediate attack (in "check") and there is no way to remove or defend it from attack on the next move.

In Figure 1, the board of Xiangqi is a gridding with 8 horizontal lines and 9 vertical lines crossing together and forming 72 crossing points. Each of the 32 pieces is put on the crossing points. Each side (red and black) has 16 pieces with 2 rooks (車), two knights (馬), two bishops (象), two cannons (炮/砲), five pawns (兵), two safeguards (仕) and one commander (將 or 帥). The above figure shows the positions of the 32 chessmen.

In Figure 2, the Chess board is chequered with 64 squares arranged in an eight-by-eight grid. Each of the 32 pieces is put in the middle of the little square before the game begins. Each side (white and black) owns sixteen pieces: one king, one queen, two rooks, two knights, two bishops, and eight pawns. The above figure shows how the pieces are set on the chessboard.

\section{The Differences in Social Structures Shown by the Chessmen}

Both Xiangqi and Chess originated in ancient times. They were not only simple 


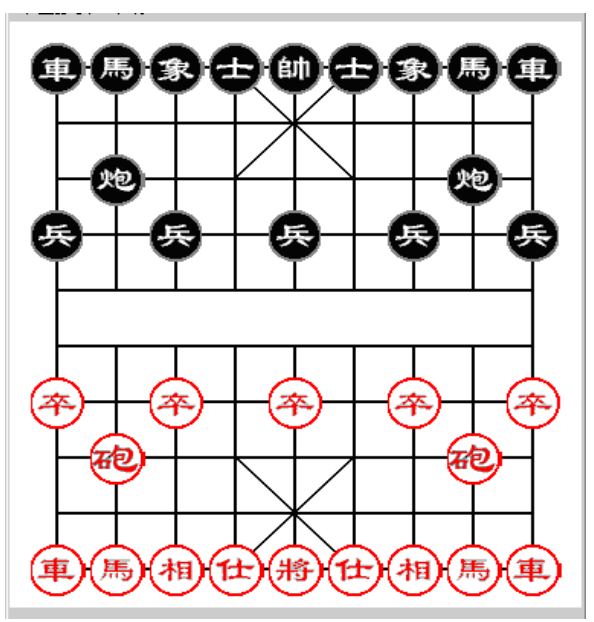

Figure 1. Xiangqi.

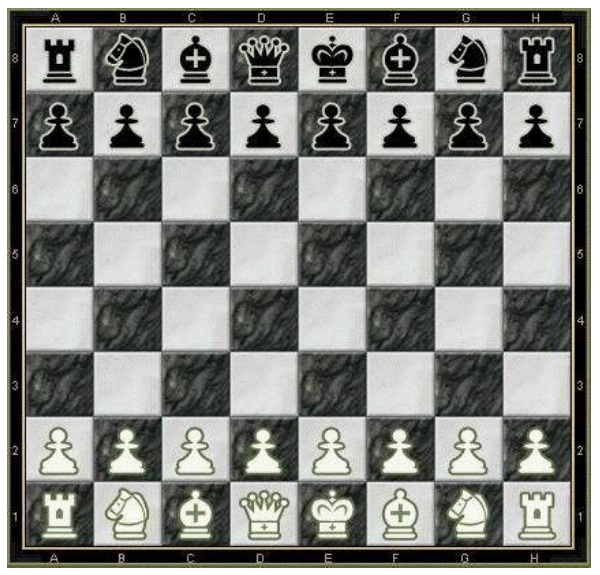

Figure 2. Chess.

games, but also cultural phenomena. Either Xiangqi or Chess is a product of people's social life. The various chessmen in the games are the symbols of the social roles. Every piece has its distinctive cultural meanings. They have different names because of the different cultural backgrounds of China and the West (Zhang, 2004). Therefore, the different chessmen in the games reflect the actual social structures of China and the West in ancient times.

\subsection{The Commander in Xiangqi and the King in Chess}

In the game of Xiangqi, for both sides, the most important piece is the commander, while in Chess the most essential chessman is the king. If one's commander or king is captured by the other side, he or she will lose the game, so the commander or king is the soul of either side. However, these two chessmen own different fighting capacities due to the rules. Actually, the king is a little more powerful than the Chinese commander. King represents the supreme leader of a country in the West, while the commander just a general of the Chinese emperor. So, the king and the commander play distinctively different roles in the two different cultural backgrounds. 
Reflected in the games, the commander can move only in a limited place (formed by 4 same squares. Chinese call it Jiugong) and can move in a $千$ routine, while the king can move across the whole board, and can move forward in eight different directions forming a sign of $\mathbb{X}$. Therefore, the two different pieces have different ranges of activity and different moving abilities. The differences exactly reflect the distinctions in the ruling patterns between China and the West when the rulers face chaos or rebellions.

When the warfare happened, the Chinese emperors would order their commanders to confront it; they would never or seldom go out for a fight personally. But the western kings would act differently from the Chinese emperors (Xu \& Yin, 2010); they would attend to the matter bravely with their soldiers and always encourage them to be brave and fight for their honor (Douglas, 1964). Take the two famous rulers Liu Bang and Alexander the Great for example. Alexander the Great (356BC-323BC) was a world famous figure. He was a king of ancient Macedonia. During his 13-year reign, he established the great Empire of Macedonia by conquering Greece, Persia, India, Egypt and other places. He was indeed a powerful image of king, while Liu Bang (256BC-195BC), a famous Chinese emperor and founder of East Han Dynasty (202BC-9AD), was an excellent leader to manage his commanders and had great wisdom of encouraging them to show their talents and gain military victory, but he himself seldom went out to the battlefields. Alexander the Great and Liu bang lived in nearly the same period of time, but they used very different ways to found their own empires. The above examples illustrate the very different ruling patterns of Chinese rulers and western rulers.

\subsection{The Chariot in Xiangqi and the Rook in Chess}

In Xiangqi and Chess, the chariot and the rook have the same way of moving, but their cultural meanings are quite different. In ancient China, the chariot played an essential role in the national military forces. It was one of the key aspects of the national power. Early in the Spring and Autumn Period and Warring States (770BC-221BC), China was divided into several big kingdoms and dozens of small kingdoms. Whether a kingdom being strong or weak was determined by the number of the chariots. In ancient China, the chariots were used not only to attack the enemies, but also to transport the army provisions and armies. Sun $\mathrm{Wu}$, the famous military strategist in ancient China, in his masterpiece The Art of War said:

In the operations of war, where there are in the field a thousand swift chariots, as many heavy chariots, and a hundred thousand mail-clad soldiers, with provisions enough to carry them a thousand li, the expenditure at home and at the front, including entertainment of guests, small items such as glue and paint, and sums spent on chariots and armor, will reach the total of a thousand ounces of silver per day. Such is the cost of raising an army of 100,000 men (Sun, 1910).

In Chess, the rook means the castle. It is also a product of wars. Since the Stone Age, the people in the European continent have started to build the castles 
to occupy the strategic positions. In France, there were more than 10,000 castles scattered across the whole country. Since the European continent mainly consisted of plains, and there was little landform of strategic importance for the armies to station, the best way to occupy a place was to build castles and then wait for their enemies. It had become a tradition to build the castles to strengthen the army forces. In the 11th century, William the Conqueror of Normandy declaimed that all the castles in England should belong to the states. This measure aimed to prevent the rise of the nobles' power and strengthen the king's rights (Douglas, 1964). As time went by, the castles became a cultural sign and were absorbed by Chess.

\subsection{The Horse in Xiangqi and the Knight in Chess}

In Xiangqi, a very key piece is the horse; it plays a battle-steed role when the game starts. Actually, in ancient Chinese wars, the horses were used to drive the chariots, charge toward the enemy's camps or to send large contingents of armed men for the military purpose. Since China was an agricultural country and industry was undeveloped, the horses were the main transportation tools. Of course, the horses were regarded as a part of national power.

In Chess, the move of the knight is similar to that of the horse in Xiangqi, but the knight is a little stronger than the horse. The knight on a chessboard represents the cavalier of medieval times. A knight was a "gentleman soldier" or member of the warrior class of the Middle Ages. Knights were asked to "protect the weak, defenseless, helpless, and fight for the general welfare of all". These were the main duties of a medieval knight, but it was very hard to accomplish them fully. Rarely could even the best knights achieve these goals.

\subsection{The Premier in Xiangqi and the Bishop in Chess}

Another two similar chessmen in the two games are the premier and the bishop; they also play similar roles in real society. In Chinese feudal society, it was a tradition that the highest-ranking rulers always appointed one or several senior officials to administer domestic and foreign affairs. The officials were called "Zaixiang or Chengxiang", who played the role of prime ministers in the royal courts. In the game, the Xiang (premier) is the symbol of these persons.

There is a bishop in the game of Chess, who represents the church. The church was a mighty force in medieval times, and religion played a large part in everyone's life. In western countries, the imperial power was always involving religion. Religion often interfered in the imperial power. For example, on December 12, 1804, the great French ruler Napoleon Bonaparte was crowned by the 7th Roman pope in Notre Dame de Paris. This implied that the religious power knuckled under the imperial power. It is no wonder that a figure that represented the concept of religion found its way into the game.

\subsection{The Guard in Xiangqi and the Queen in Chess}

The guard and the queen are two different pieces in terms of their own way of 
move, but they have one obvious similarity: both of them are next to the commander or the king on the chessboard. The guard, in the game of Xiangqi, is the commander's bodyguard whose main job is to protect the commander. It is also an epitome of Chinese social structure. In Chinese feudal society, the emperor set up his royal guard team to protect himself; the royal guards were close to him that he would order them whenever he was in danger. This is also reflected in the game of Xiangqi. For each side, there are two guards next to the commander.

The queen is the only piece on the chessboard during a Chess game that represents a woman. She is the most powerful piece of the game, worth 9 points and able to move any number of squares vertically, horizontally or diagonally. The queen in medieval times often held a powerful, yet precarious position. The king was often guided by her advice, and in many cases, the queen played games of intrigue at court. But the king could set his wife aside or even imprison her in the nunnery with the approval of the church (and without the queen's approval), and many queens in history schemed merely to hold their place at court. The suggestions of queens working either for or against their kings are well noted throughout medieval times. Reflected in the game, the queen is the most powerful piece among all pieces.

\subsection{The Horse in Xiangqi and the Pawn in Chess}

Two unique pieces should be paid more attention to. They are the horse in Xiangqi and the pawn in Chess. Some special moves of the two pieces reflect the different cultural phenomena of China and West. In the game of Chess, there are eight pawns. The rules say when the pawn moves on the baseline of the opponent's field, it would never be a little and weak pawn. The moment the pawn touches the baseline, it will gain a right to promotion that will make it become a knight, a bishop, a rook, or even a powerful queen! The rules reflect the western incentive mechanism. Indeed, in western culture, when the soldiers make great contributions to the military victory, they will be awarded. Under the cultural tradition, the western society has produced a large number of excellent generals who were first obscure pawns, such as Napoleon Bonaparte. He was originally a sub-lieutenant when he joined the army in 1785. With his excellent talent and extraordinary contributions to the French Empire he later became a great military leader.

In contrast, the horse in Xiangqi is part of the main force with an awe-inspiring reputation extending in every direction. However, one special rule makes its might fade. As Figure 3 shows, without the obstacle in front of the piece, the horse can control 8 points, but with some other piece (the cannon) just in front of it, the horse can control only six points (the moon-shaped mark). This move is also a reflection of ancient Chinese feudal social conditions. The talents (just like the competent horse) were always envied and elbowed out by some bigwigs and they would not have the conditions to render a service to the country. 
In Figure 3, the moons are the points that the horse can move to, while the is the position where the horse can't arrive because of the obstacle cannon.

\section{The Different Thinking Patterns Reflected in the Games}

The different appearances of the pieces reflect the different thinking patterns between Chinese and western people. The chessmen of Xiangqi are usually made of wood or stone with a Chinese character carved on one side of the little round wooden or stone pieces and printed in red or black colors. Compared with the Xiangqi pieces, the Chess pieces are the imitations of the real castle or knight or other objects. These pieces are made according to the shape of real items. So their appearances are attractive and verisimilar. In other words, the pieces of Xiangqi are 2-dimensional while the Chess 3-dimensional. These appearances have been accepted by Chinese people and the western people respectively from ancient to modern times. From the appearances of the two games, it can be concluded that the Chinese people focus more on the similarity between the objects while the western people stress the diversity. In the games, the different forms of the chess pieces exactly embody the different concepts of similarity and diversity.

The different thinking patterns between Chinese and westerners can also be found in the position of the pieces. The Xiangqi pieces are put on the crossing points of the board. In Chinese people's mind, they try to find a fixed reference object to make their behavior conform to the social rules; however, the Chess pieces are usually put in one square of the chessboard. It indicates that the westerners try to find their own position to show themselves in a relatively big range. They intend to seek for relatively free room in order to display their individualities while the Chinese intend to obey the rules (Li, 2008).

Another aspect that reflects the different attitudes of Chinese people and westerners toward "freedom" and "rule" is the move of the pawn. Either in Xiangqi or in Chess, the pawns are the least important pieces at the beginning of the game, but their moves in the two games are quite different (Feng, 2000). The pawns in Xiangqi are allowed to move one step forward, and when they arrive at the baseline of the opponent's domain, they will never go back but to die of their uselessness. On the other hand, the pawns in Chess have the right to move one or two steps when they are in their original positions. This option makes it more

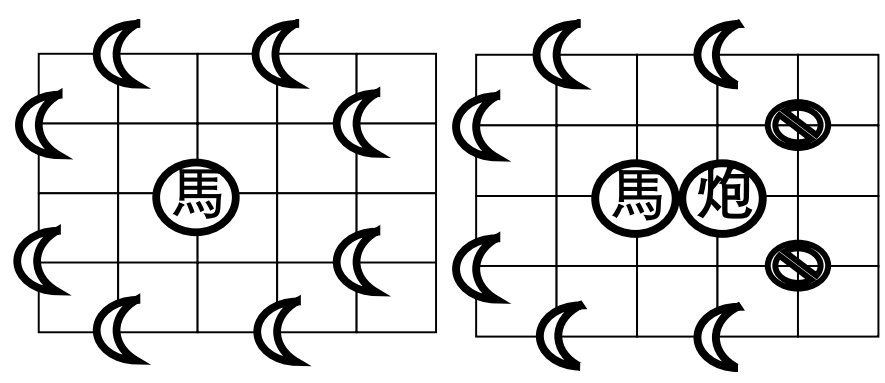

Figure 3. The move of the horse in Xiangqi. 
convenient to adapt themselves to the changing circumstances. Comparatively speaking, the pawn in Chess has more freedom on the board than it has in Xiangqi. It is also a reflection of the real society of the West and China. The Chinese cultural tradition conduces obedience while the western culture conduces individualism.

\section{The Geographic Differences Displayed in the Games}

The character of a nation is the result of a certain type of environment. In fact, all national qualities have an organic unity, which finds its explanation in the kind of natural, social and political soil that nourishes them (Zhang, 2004). The following analysis will illustrate how the natural environment and the warfare patterns interact and how their interactions are reflected in the two board games.

\subsection{The Importance of the River in Wars in Ancient China}

We can obviously see a "river" on the Xiangqi board which divides the whole battlefield into two parts. This river is called "Chu He-Han Jie", (the Riverbank of Chu Kingdom and the Abuttal of Han Kingdom. The pieces scatter along the river and stand facing their enemies. This river is a boundary of the two parties' sphere of influence. The "river" on the chessboard is a cultural sign which represents an important factor which would determine the ending of a war in China. For example, according to The Record of the Three Kingdoms, in 208, Cao Cao (155AD-220AD), the leader of Wei Kingdom, one of the most famous politicians and strategists who had unified North China, launched a famous war called "The War of the Red Cliff” against Sun Quan (182AD-252AD), the leader of $\mathrm{Wu}$ Kingdom who occupied Southeast China (Chen, 1959). Though the number of Cao Cao's soldiers was much larger than Sun Quan's, when Cao Cao led his soldiers to cross the Yangzi River, many of them died from the unfavorable natural environment and their unfamiliarity with the sea warfare (Chen, 1959). As a result, Cao Cao was defeated by Sun Quan. This is a classic war in which the few defeated the many.

The river is a very critical factor that influenced the ending of the war. Actually, China is vast in territory and rich in mountains and rivers. The great number of rivers in China has deeply influenced the warfare patterns. Some famous rivers are the Yellow River, which flows across the northern Chinese territory, the Yangzi River, which almost divides China into two parts, and the Hanjiang River which originates from Hanzhong, a city located in the southwest of Shaanxi Province, and flows into the Yangzi River. There is no doubt that many factors will determine the ending of a war, but the rivers play an essential role. Some classic Chinese idioms like "break the caldrons and sink the boats after the river", "fight with one's back to the river" and "give a heavy strike when the enemies haven't finished crossing the river" give testimony of how important the rivers were in the wars in ancient China. As an essential factor that would affect the outcome of a war, the river finds its way in the classic Chinese game Xiangqi. 


\subsection{The Importance of the Central Battlefield in Wars in the West}

When the game of Xiangqi begins, both sides will put their best leg forward to control the riverbank so as to make their military for cestationed on the battlefield. Because of the strategic position of Chu He-Han Jie, in the beginning of the game, both parties race to control this military position.

But, when the game of Chess begins, the pawns, knights or bishops will try to occupy the centre of the chessboard in direct or indirect ways to get the space advantages. One of the opening principles in Chess is to control the central battlefield as soon as possible. The game reflects the geographic features of the European continent, where Chess is widely popular. The European continent mainly consists of several great plains, such as the Western European Plain, Eastern European Plain and Middle European Plain. The total areas of the plains whose sea level is below $200 \mathrm{~m}$ take up $60 \%$ of the whole European continent. Therefore, in ancient western wars or battles, the military generals paid more attention to the wide fields and tried to hold the strategic positions with all their forces and then built the solid castles to wait for the enemies.

\section{Conclusion}

Both Xiangqi and Chess are the precious spiritual wealth of human beings (Hooper \& Whyld, 1992). They are the products of the historical development of Chinese and western civilizations. The two games contain so many cultural elements and have been deeply influenced by the different cultures and customs of China and the West. The different pieces are the symbols of the different social classes that play different social roles in different societies, and the different moves of these pieces also reflect the different thinking patterns and the geographical features of China and the West. In a word, these two games prominently demonstrate the different cultural backgrounds, including the distinctions in social classes, thinking patterns and geography between China and the West.

In the process of the globalization, with the rapid development of China, the cultural communication between China and the West will become deeper and more frequent. Under such circumstances, Chinese people need to learn more about the western culture and the westerners also need to know more about the Chinese culture. Only by this way can China and the West better know and understand each other, accept the differences as well as similarities in their cultures, and further develop a healthy, harmonious and win-win relationship in a variety of activities.

As a kind of cultural phenomenon, the two games-Xiangqi and Chess-are the products of the development of the cultures of China and the West. When an increasing number of Chinese play or are learning to play Chess for either entertainment or intelligence competitions, it is necessary for them to be acquainted with the rich cultural connotations behind the game. Likewise, as more westerners show keen interest in Chinese culture, Xiangqi could offer a window 
through which to catch a glimpse of Chinese history and culture. To make more Chinese people know Chess and more westerners know Xiangqi will be an interesting issue to help the menhance their mutual understanding in the global village.

\section{Conflicts of Interest}

The author declares no conflicts of interest regarding the publication of this paper.

\section{References}

Ah, C. (2019). The Chess King. Shanghai: Shanghai Joint Publishing Co.

Chen, S. (1959). The Record of the Three Kingdoms. Beijing: Zhonghua Book Company.

Douglas, D. C. (1964). William the Conqueror. Los Angeles: University of California Press.

Feng, J. L. (2000). A Biography of Chinese Chess Masters. Beijing: Writers Publishing House.

Hooper, D., \& Whyld, K. (1992). The Oxford Companion to Chess (2nd ed.). Oxford, UK: Oxford University Press.

Li, Y. C. (2008). A Panorama of Chinese Culture. Dalian: Dalian University of Technology Press.

Lin, F. (1999). A History of International Chess. Shanghai: Shanghai Lexicographical Publishing House.

Sun, W. (1910). The Art of War. Trans.Giles, L.M.A.: Maggies Books.

Xu, J. L. (2004). Ancient Chinese Chess. Beijing: Commercial Press.

Xu, Y. X., \& Yin, Y. J. (2010). The Tao Te Ching-Lao Tzu. Beijing: China Intercontinental Press.

Zhang, C. Y. (2004). A Comparative Study of Western and Chinese Cultures. Changsha: Hunan People's Publishing House.

Zweig, S. (2005). Chess Story. New York: NYRB Classics. 